\title{
Concept of a Sino-German Summer School on Multiscale Processes in Oceans and the Atmosphere
}

\author{
Gerrit Lohmann ${ }^{1,2, *} \mathbb{D}$, Xueen Chen ${ }^{3}\left(\mathbb{D}\right.$, Xun Gong ${ }^{1}\left(\mathbb{D}\right.$ and Shuang $\mathrm{Li}^{3}$ \\ 1 Alfred Wegener Institute Helmholtz Centre for Polar and Marine Research, 27570 Bremerhaven, Germany; \\ GongXun.Allen@awi.de \\ 2 Department of Environmental Physics, University of Bremen, 28359 Bremen, Germany \\ 3 College of Oceanic and Atmospheric Sciences, Ocean University of China, Qingdao 266100, China; \\ xchen@ouc.edu.cn (X.C.); happy77@ouc.edu.cn (S.L.) \\ * Correspondence: Gerrit.Lohmann@awi.de; Tel.: +49-471-4831-1758
}

Received: 10 August 2020; Accepted: 23 September 2020; Published: 24 September 2020

\begin{abstract}
A concept for an interdisciplinary summer school for "multiscale processes in oceans and the atmosphere" is presented. It aims to deepen students' understanding of scientific issues as well as their experience in multicultural communication. The theme covers climate evolution, which is partially dominated by far-reaching anthropogenic changes and their possible consequences on the Earth's system. An integrated approach helps to change rigid subject-specific mindsets among faculties and students and across cultures, so as to broaden their horizons in both research and life. Research has shown, however, that the development of intercultural competence in students does not happen automatically but needs to be fostered and supported. Therefore, a primary goal is also to provide young researchers from several countries (mainly China and Germany) with the opportunity to gain more indepth knowledge on research in Germany, to be exposed to scientific culture, and thus to prepare for foreign research visits either during the PhD phase or as postdoctoral fellows, supporting the internationalization of education and opportunities in marine sciences. Finally, the students have the chance to further develop their scientific profiles by attending scientific talks, lab exercises, and excursions and by combining rigorous scientific disciplines with the awareness of multidisciplinary issues related to the topic of global climate change.
\end{abstract}

Keywords: interdisciplinary summer school; multicultural communication; internationalization of education; multiscale processes in oceans and the atmosphere

\section{Introduction}

A series of summer school programs aim to foster dialogue and exchange between students and scientists from China and Germany. These programs deepen the students' understanding of scientific issues as well as their experience in multicultural communication, so as to broaden their horizons in both research and life. We provide interdisciplinary training in an international context that focuses on the observation, modeling, and understanding of the challenges and perspectives in "multiscale processes in oceans and the atmosphere". Climate change provides an important research area since human activities continue to affect the Earth's energy budget by changing the emissions and resulting atmospheric concentrations of radiatively important gases and aerosols and by changing land surface properties [1].

The natural climate creates the most important general conditions for human activities. For that reason, climate has been one of the most fundamental themes of human reflection over the centuries. Furthermore, research findings on the relationship between climate and conflict are diverse and contested, and intensifying climate change is estimated to increase future risks of conflict [2]. 
The educational goal of this summer school is to communicate a comprehensive overview of key scientific issues related to climate processes and is addressed to doctoral students and advanced Master students, going beyond their own fields of study. Our summer school provides a case study for the issue, where, additionally, the participants have a different cultural background and are mainly from Germany and China. The summer school is organized in the framework of the Sino-German Cooperation in Marine Sciences (SGMS), which was established in 2011. Since then, the collaborating institutions strive for joint research projects and jointly contribute to summer school programs and symposia. Joint graduate education is the main aim of the SGMS. The involved institutes are the University of Bremen, the Ocean University of China in Qingdao (OUC), the Christian Albrechts University in Kiel, the University of Hamburg, the Carl von Ossietzky University in Oldenburg, as well as the research centers Leibniz Centre for Tropical Marine Research in Bremen, the GEOMAR Helmholtz Centre for Ocean Research in Kiel, the Key Laboratory of Physical Oceanography (POL), the Alfred Wegener Institute for Polar and Marine Research (AWI), the Center for Marine Environmental Sciences (MARUM), and the Kiel-based Cluster of Excellence "The Future Ocean".

In the last 10 years, the abovementioned German institutes have had more than 74 master and $77 \mathrm{PhD}$ student exchanges with the OUC. At this particular summer school, we had 12 students from AWI and 15 from China. For the whole week, 12 lecturers from Germany and 4 from China were involved. The AWI students and lecturers were international: 7 students and 4 lecturers stem from other countries, some with very different cultural backgrounds (India, China, The Netherlands). The SGMS unites previous, present, and future bilateral educational activities between the German and Chinese partners and strives to continuously enhance cooperation in the fields of higher education and research and development in marine sciences. Therefore, the SGMS is committed to building our activities into a sustainable, broad-based, and long-term cooperation that allows individual researchers at all levels to be aware of the possibilities for marine research in China and Germany.

On the basis of existing collaboration, lecturers from Germany and China (and their international colleagues) gave academic talks under the theme of "multiscale processes in oceans and the atmosphere", covering a wide range of topics (Figure 1) ranging from regional to global and from weather to millennial time scales. By multidisciplinary training in marine sciences and cultural communication, participating young scientists (postdoc researchers, $\mathrm{PhD} /$ master candidates) joined in
(a) multidisciplinary training in marine sciences;
(b) joint teaching by Chinese and German, and international colleagues;
(c) understanding research projects and infrastructure in German institutes;
(d) a networking opportunity for early-career scientists and participants;
(e) a cross-cultural dialogue through personal and scientific interactions with peers. 


\begin{tabular}{|c|c|c|}
\hline 24.09 .19 & TUESDAY & Lecturer \\
\hline \multicolumn{3}{|c|}{ Titles } \\
\hline 9:00 - 9:30 & Welcome \& Introduction & Organizer \\
\hline \multirow[t]{2}{*}{$9: 30-11: 00$} & The Earth Climate System and its Components & Dr. Martin Werner \\
\hline & coffee break & \\
\hline \multirow[t]{2}{*}{$11: 30-12: 00$} & Introduction to AWI \& Helmholtz Association & POLMAR team \\
\hline & L U N C H & \\
\hline \multirow[t]{2}{*}{$13: 00-14: 30$} & The Marine Carbonate System & Prof. Dr. Dieter-Wolf Gladrow \\
\hline & coffee break & \\
\hline $15: 00-16: 30$ & The Global Carbon Cycle & Prof. Dr. Boris Koch \\
\hline \multirow[t]{2}{*}{25.09 .19} & WEDNESDAY & \\
\hline & Titles & \\
\hline \multirow[t]{2}{*}{$9-10: 30$} & $\begin{array}{l}\text { Icy hollows: Under-ice creatures in the Arctic and } \\
\text { Antarctic Oceans }\end{array}$ & Dr. Hauke Flores \\
\hline & coffee break & \\
\hline \multirow[t]{2}{*}{$11-12: 30$} & Plankton communities in the polar oceans & Dr. Christine Klaas \\
\hline & L U N C H & \\
\hline \multirow[t]{2}{*}{$13: 30-15: 00$} & Ocean acidification: The ugly side of global warming & Prof. Dr. J. Bijma \\
\hline & coffee break & \\
\hline $15: 30-17: 00$ & The Big picture & Prof. Dr. Victor Smetacek \\
\hline \multirow[t]{2}{*}{26.09 .19} & THURSDAY & \\
\hline & Titles & \\
\hline \multirow[t]{2}{*}{$9-10: 30$} & Ice in the climate system & Prof. Dr. F. Wilhelms \\
\hline & coffee break & \\
\hline \multirow[t]{2}{*}{$11-12: 30$} & $\begin{array}{l}\text { Paleoclimate dynamics - identifying driving } \\
\text { mechanisms of climate change }\end{array}$ & Prof. Dr. Gerrit Lohmann \\
\hline & coffee break & \\
\hline $12: 45-13: 00$ & $\begin{array}{l}\text { Atmospheric deposition and Oceanic response in the } \\
\text { northwest Pacific }\end{array}$ & Prof. Dr. Huiwang Gao \\
\hline \multirow[t]{2}{*}{$13: 00-13: 15$} & $\begin{array}{l}\text { Changing Phases of Atlantic Meridional Overturning } \\
\text { Circulation and its Impact on Global Climate }\end{array}$ & Prof. Dr. Xianyao Chen \\
\hline & transfer to Klimahaus & \\
\hline $14: 00-18: 00$ & visit of Klimahaus & \\
\hline \multirow[t]{2}{*}{ 27.09.19 } & FRIDAY & \\
\hline & Titles & \\
\hline \multirow[t]{2}{*}{$9-10: 30$} & Communicating my science to the media & Sina Löschke \\
\hline & coffee break & \\
\hline \multirow[t]{2}{*}{$11-12: 30$} & Students' talks & Students \\
\hline & L U N C H & \\
\hline $13: 30-13: 45$ & $\begin{array}{l}\text { Numerical investigation of internal tides in the } \\
\text { northwest Pacific Ocean using a global circulation } \\
\text { and tide model }\end{array}$ & Prof. Dr. Xue'en Chen \\
\hline $13: 45-14: 00$ & $\begin{array}{l}\text { Hyperpycnal plume at the Yellow River Mouth } \\
\text { triggered by dam regulation: In-situ observations }\end{array}$ & Prof. Dr. WANG Houjie \\
\hline $14: 15-14: 30$ & $\begin{array}{l}\text { New insights on sediment flux through the Bohai } \\
\text { Strait }\end{array}$ & Dr. Wu Xiao \\
\hline $14: 30-15: 00$ & $\begin{array}{l}\text { Summer School Certificate ceremeny, Group Photo \& } \\
\text { farewell }\end{array}$ & Organizer \\
\hline
\end{tabular}

Figure 1. Program of the interdisciplinary Sino-German summer school in Bremerhaven (Germany) in 2019. 


\section{Scientific Concept}

The Earth's climate is dynamic, and the effects of climate change are pervasive. However, Earth's climate system is also complicated by many interacting components, feedback, and forces. These climatic factors and processes constrain environment changes by different weights in distinct regions and also at various time scales, as recorded by climate archives (Figure 2). Paleoclimate data put our current climate into a long-term perspective. It analyses hazardous tipping points and provides additional information for societal decision-making based on knowledge, which is largely limited to the observational constraints of the last 50 years. For example, a recent study has provoked that global patterns of temperature variability have largely reduced from the Last Glacial Maximum ( 23,000-18,000 years ago) to Holocene (since 11,000 years ago) [3].

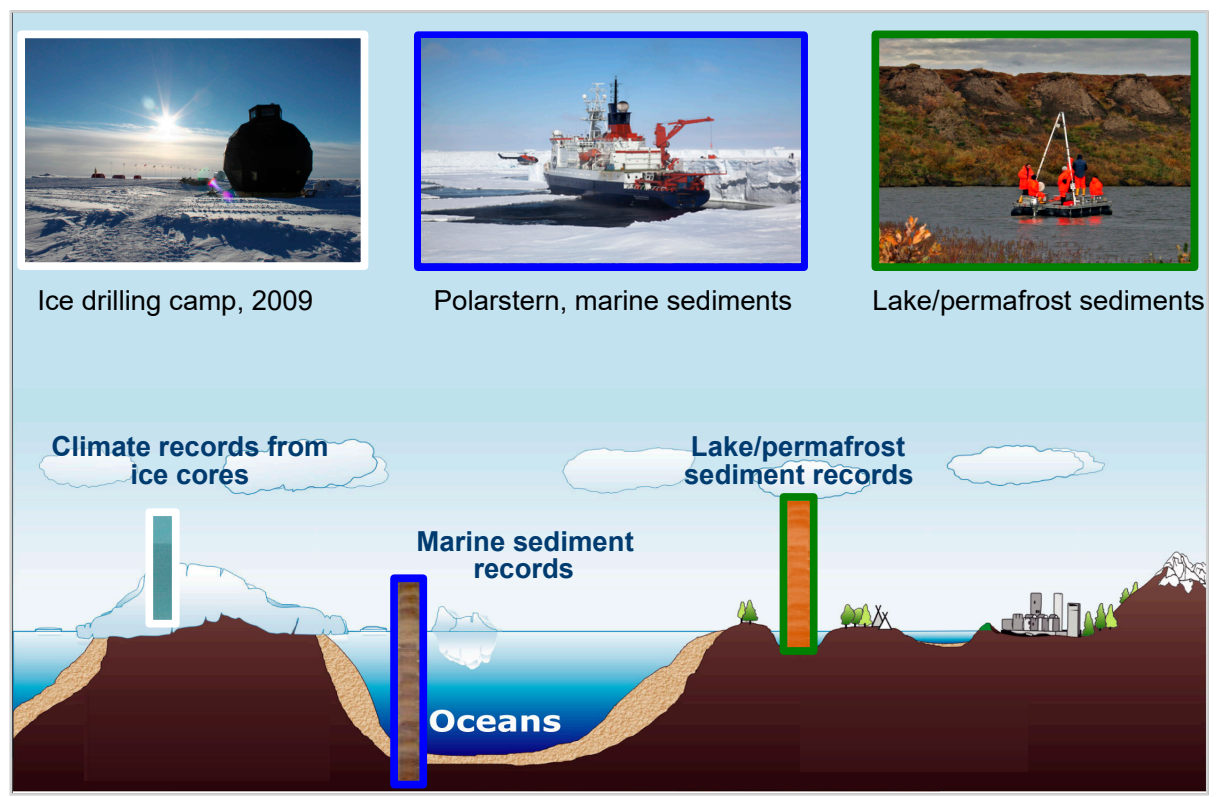

Figure 2. Example of paleoclimate archives revealing the climate of the past. Ice cores can be used to reconstruct the past atmospheric greenhouse gases in air bubbles and through the analysis of the ice composition the regional temperature. Sediment cores in the oceans and lakes provide large-scale patterns of ocean circulation and regional environmental changes (e.g., [4]).

Together with the cryosphere, oceans and the atmosphere are the most important factors in the Earth's climate system. Thus, multiscale processes in oceans and the atmosphere and their combined effect is key to understanding climate trends, variability, and extreme events. We need information from past trends, variability, and shifts. As discussed in the International Panel on Climate Change (IPCC) report [1], flooding and drought events have become more frequent along with the ongoing global warming, and they are projected to make more severe impacts on human activities in the future of a persistent atmospheric $\mathrm{CO}_{2}$ rise, as in the past decades. In particular, this is a challenge for mid-latitude and monsoon areas. In the Atlantic realm, examples in observations involve the early Arctic warming in the 1930s, the pronounced North Atlantic cooling in the 1970s, and the ongoing warming over the last two decades. A rapid change in the Arctic sea ice and extreme conditions of internal variability can affect large-scale ocean circulation [5]. This, then, affects the variability of climate over Europe and the North Atlantic.

Accordingly, the summer school aims to understand the roles of oceans and the atmosphere in the Earth's climate system from the past to the future. Specifically, we focus on regional-to-global changes in oceans and the atmosphere and their coupled system on different time scales (e.g., [5-7]). For instrumental, observational, and modeling efforts to access global climate change from the past to the future, see Figure 3. The contribution of the paleoclimate is to bring current and future changes 
into a context by quantifying natural variability. We apply numerical models of the Earth's system [8]. The level of description varies from conceptual (e.g., $[9,10])$ to model intermediate complexity [11] to complex models [12].

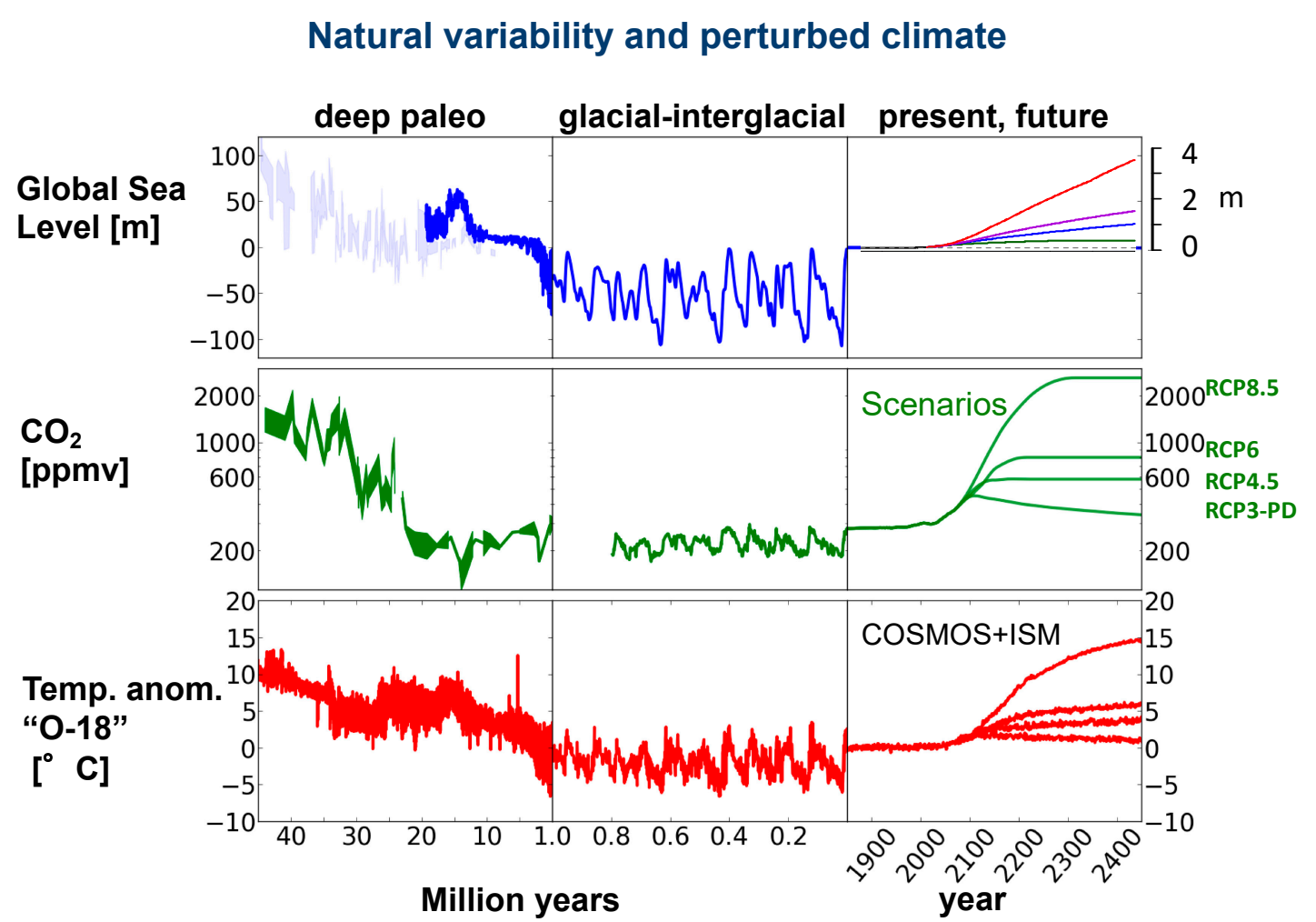

Figure 3. Sea level, $\mathrm{CO}_{2}$, and temperature at different time scales. The time scales are called "deep paleo" (50 to 1 million years ago), indicating a cooling trend, glacial-interglacial variability covering the last 1 million years, and, finally, model scenarios for present and future climate evolution with the Earth System Model COSMOS + ISM [7]. Note that future scenarios strongly deviate after the year 2100.

Natural processes and their anthropogenic impact the Earth's climate and their fingerprints are evident in biodiversity and economic issues. In order to properly address this question, one needs quantitative information regarding the amplitude and rapidity of natural variations of temperature in the oceans, over the continents, and in the cryosphere. The best way to ascertain the extent of past changes is through the inspection of time series of documentation of such environmental observations.

Our multidisciplinary approach refers to the work based on observational methods, e.g., remote sensing, instrumental measurements, marine sediments, in combination with modeling studies as well as biogeochemical parameters related to natural climate processes and anthropogenic impacts. In the summer school program, the lectures are accompanied by onsite visits to gain a first-hand demonstration of the techniques and, in several cases, practical demonstrations and experiments to be conducted by the students themselves. Students with educational backgrounds in biology, physics, and geology will gain a broad view of complementary disciplines that enriches and sharpens their scientific profiles.

As an additional concept, students work in divided groups to develop ideas on up-to-date topics related to multiscale processes in oceans and the atmosphere, e.g., the roles of oceans, the atmosphere, and sea ice in a warming climate. Examples are climate trends and uncertainties from the past to the projected futures [2] (Figure 3). Finally, key atmosphere and ocean factors to the climate in Germany and China are evaluated. The scientific highlights are accompanied by a range of activities aimed at integration and communication among the students and lecturers; all students come prepared 
to present their own research, and an entire session is dedicated to the crucial aspect of scientific communication (Figure 1).

\section{Research Background for the Summer School}

Climate has a spatial and temporal dimension, which fluctuates in a wide range of spatial and temporal scales (Figure 4). Spatial scales vary from local to regional to continental. Time scales vary from seasonal to geological. The spatiotemporal dimension of atmospheric phenomena is defined by their typical spatial extension (e.g., the diameter of a high-pressure area), which is linked to a structure whose magnitudes can be specified as spatial scales. The time scale of an atmospheric process is the order of magnitude of its lifetime. In addition, it is also possible to specify the spatial and temporal resolution with which a system is to be viewed. The word "scale" in this context means the order of magnitude or scale. Basically, climate represents a space-time continuum, so that fixed scale limits do not occur in the system. Larger and smaller systems influence each other so that the transitions between differently scaled phenomena are smooth, and the approach is usually based on the question [11].

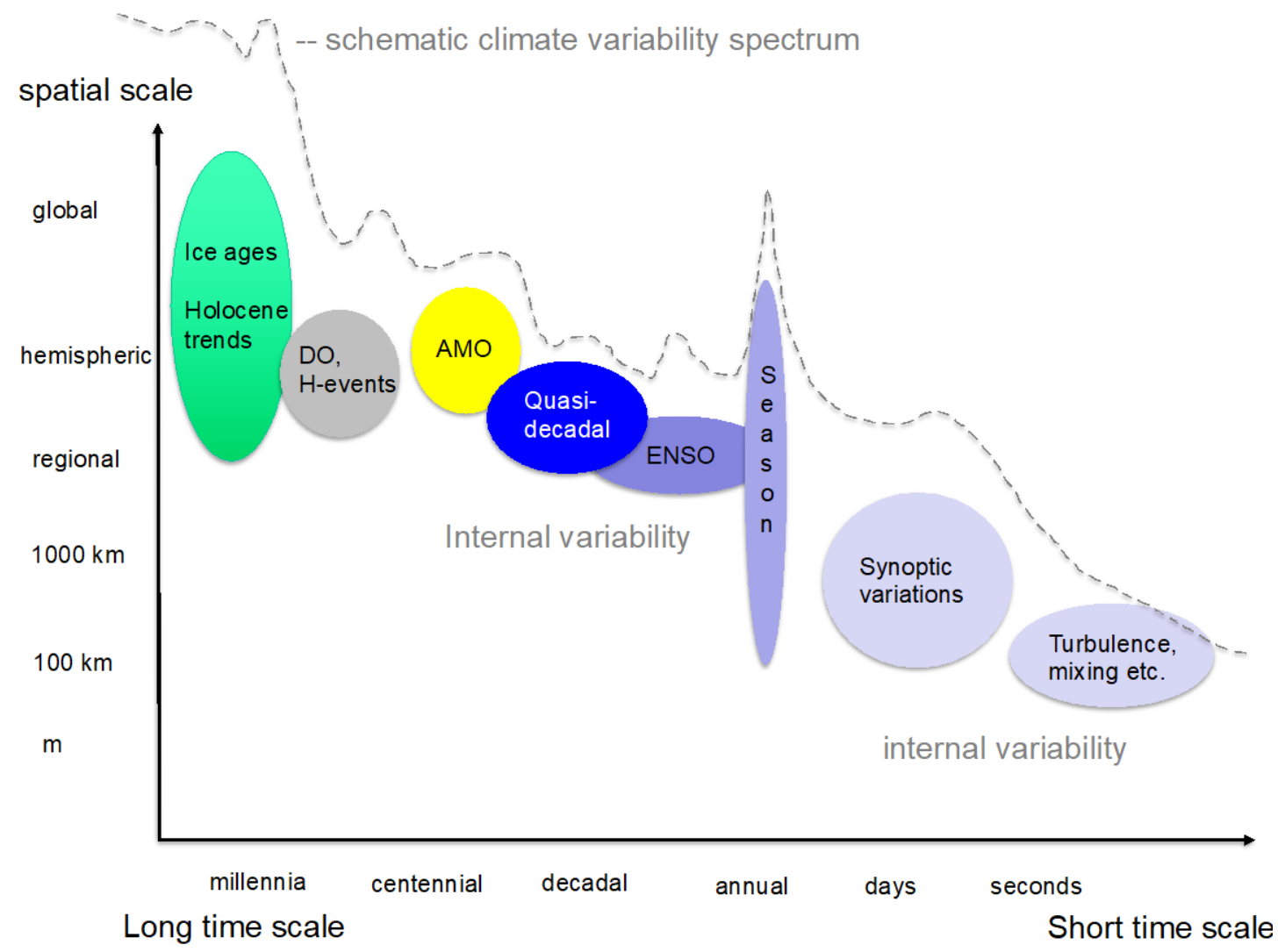

Figure 4. Temporal-spatial scales. Any climate (or Earth system question) has a typical spatial scale, e.g., focusing on a geographic region or processes on specific scales, such as turbulence. Schematic diagram of the spatiotemporal scales considered. DO: Dansgaard-Oeschger, H: Heinrich events; AMO: Atlantic multidecadal oscillation; PDO: Pacific decadal oscillation; ENSO: El Niño-southern oscillation. The annual and astronomical cycles are externally driven and have quasiglobal impact. The dashed line shows a schematic power spectrum with more variability on long time scales. The temporal scale is quite often related to the spatial scale: changes on longer timescales are more global than regional. For example, turbulence has a small spatial and temporal scale compared to synoptic weather systems. This relation is a general tendency unless external force is considered. Then, a short-term event like a volcano may have a global effect.

The chosen topic is inherently interdisciplinary, requiring experimental and observational capabilities, theoretical understanding, and integration through modeling (Figures 2 and 3). 
The discussion in this summer school tackles essential interests for both basic research as well as for decision-making and application to societal issues. Theoretical input is given through lectures introducing the key scientific issues by a range of multidisciplinary research topics (Figure 1).

The institutions for this summer school, e.g., OUC in China and AWI in Germany, have been involved in several European and Chinese research initiatives, uniting multiple disciplines and institutes. The themes of the summer school are linked to major projects. The science behind this research covers deep-time paleoclimate questions, glacial-interglacial variability, and current and future climate change (Figure 3). Through our effort, scientists from a variety of disciplines try to cooperate and exchange views on the common theme of Earth System Science, which leads to a better understanding of processes in a global context [13]. One challenge for interdisciplinarity is that the set of perspectives, approaches, and values that characterize one field do not align exactly with those of another field. To the extent that these are implicit and unarticulated, as well as unaligned, they can lead to misunderstandings, also differing on standards of evidence, acceptable forms of reasoning, appropriate means of conveying findings, and even on what vocabulary to use [14]. A scientist in modern Earth System Science has to overcome these distinctions for any true collaboration and collaborative problem-solving.

Multidisciplinary research around the topics addressed in this event is a focus of research in several institutes and departments of the Chinese and German institutes involved. In recent years, a number of research projects have been carried on based on Sino-German joint efforts, for instance, the Sino-German Project "Paleoclimatic Evolution of the Arctic and Subarctic Oceans Since the Last Glacial Period" [15]. Furthermore, the climate modeling work in AWI enables "data-model syntheses", which are crucial for exploring the underlying mechanisms of observed changes in proxy records. A related project deals with the North Pacific ocean in warming climates during the Quaternary. This project aims to increase the insight into North Pacific oceanographic and biogeochemical processes during a warmer-than-present climate in the geological past. As the largest oceanic net sink of atmospheric $\mathrm{CO}_{2}$, the subarctic North Pacific's sensitivity to forcing changes and feedback to background climate is an important but largely open question in assessments of the global climate, both in the past and in the future.

\section{Educational Goal}

It is important that climate change goes well beyond the natural science context. There are scenarios where climate change can induce conflicts due to water stress, land use and food security, natural disasters, and environmental migration [16]. The temporal-spatial pattern spread from a small-scale has directly impacted areas in terms of global changes, linking abrupt and fast small-scale changes to smooth global changes.

Since this is an inherently multidisciplinary challenge, young scientists, who will act as decision-makers in the future, need to be exposed to a wide range of disciplines involved at an early stage of their professional careers. We do this by including experts from diverse disciplines, like biogeochemistry, physical oceanography, geology, biology, coastal engineering, and international law of the sea, as lecturers and providing a good mix of theoretical and practical teaching, as well as a demonstration of case studies (Figure 1).

Our intention is to contribute significantly to the internationalization of education and opportunities in marine and climate sciences. Furthermore, we provide young researchers from both countries the opportunity to gain more indepth knowledge about the research infrastructure in Germany, to be exposed to the scientific culture of several research institutes and groups, and thus to prepare for foreign research visits either during the $\mathrm{PhD}$ phase or as postdoctoral fellows. Thus, participants have the chance to further develop their scientific profiles by attending scientific talks, lab exercises and excursions, and by combining rigorous scientific disciplines with the awareness of multidisciplinary issues related to this highly relevant global topic. Moreover, one of the key educational targets is to enhance the cultural dialogue between both countries since intercultural 
competence is a central element for future joint activities. By bringing together young scientists and lecturers for an extended period is the perfect way to cross cultural barriers and develop personal, long-lasting friendships. Our experience is that a summer school can indeed be a good start to overcoming fears and uncertainty in international communication or before going abroad. Intercultural competence is necessary to communicate effectively and appropriately in intercultural situations based on one's intercultural knowledge, skills, and attitudes [17]. Basic cultural assumptions may be questioned in a reflection process, which can then lead to a change in perspective. Through the new media, one might think of the future development of education for everybody. This could be a starting point for learning different systems of knowledge based on intellectual cooperation and dialogue using the available information of marine and climate sciences [18].

\section{Benefit}

Sino-German cooperation in marine sciences is still in its early stages, and it is imperative that we develop widespread cooperation and understanding between researchers at all levels that will initiate and sustain long-term projects on scientific issues of complementary and joint expertise. Both countries look back on a long tradition of excellence in marine research, but it has been less than a decade that active exchange and institutional support have been built up. Since the Sino-German Initiative on Higher Education in Marine Sciences was initiated, these activities have been ensured greater success, leading to joint publications in high-ranking international journals, research visits between senior scientists, and the exchange of Master and PhD students. However, there is a need for understanding intercultural communication, which is how scientific progress is obtained. It is a continuous process, especially for individuals who are culturally different from each other on such important attributes such as their value orientations, preferred communication codes, role expectations, and perceived rules of social relationships [19]. It is necessary to confront ourselves with the science of climate (and Earth system) change on a high interdisciplinary level, especially as the climate problem will become more serious in the future and as students around the world urge governments to do more about global warming [20,21].

The Center for Sino-German Cooperation in Marine Sciences (SGMS), under the umbrella of which this school is run, is committed to building these fledgling activities into a sustainable, broad-based, and long-term cooperation that allows individual researchers at all levels to be aware of the possibilities for marine research in China and Germany. By making participating students aware of the research potential and infrastructure in the Sino-German context, we will greatly increase their chances of developing the personal and professional contacts that they follow-up in their individual careers. Our intention is that these activities strengthen and reinforce joint research activities beyond the individual countries.

\section{Conclusions}

A concept for an interdisciplinary summer school for "multiscale processes in oceans and the atmosphere" is presented. The theme covers the climate and Earth system evolution from past, present to future, its driving factors and inherent fluctuations. Students have the chance to further develop their scientific profiles by attending scientific talks, discussions, lab exercises, and excursions. One further aim is to guide young researchers in their work as well as in their engagement with the practical, ethical and intellectual challenges inherent in research. Basic points are

(1) Communicating research in a transparent, fair, full and unbiased way;

(2) Reliability in ensuring the quality of research: design, methodology, use of resources;

(3) Respect for colleagues, participants, and the environment.

Furthermore, our concept provides a case study in a more general approach [22] on how to prepare global-ready students, postgraduate students, and researchers who have an interest in intercultural and global competence in a highly interdisciplinary manner. An integrated approach helps to change rigid 
subject-specific mindsets among faculties and students. Gaining holistic insights into the Earth system requires the integration of observations, paleoclimate data, analysis tools, and modeling simulations. Finally, intercultural competence is now considered a behavioral trait that "almost no one can avoid" because it includes the personal prerequisites for mastering intercultural situations [22,23].

Author Contributions: Conceptualization, G.L. and X.C.; methodology, G.L., X.C., X.G., and S.L.; writing-original draft preparation, G.L., X.C., X.G., and S.L.; writing-review and editing, G.L., X.C., X.G., and S.L.; project administration, G.L. and X.C.; funding acquisition, G.L. and X.C. All authors have read and agreed to the published version of the manuscript.

Funding: This research was funded by the Sino-German Center (GZ1597) and BMBF through NOPAWAC (03F0785A) and PACES.

Acknowledgments: We acknowledge support from Katharina Kirchhoff, Claudia Hanfland, Claudia Sprengel, and Dörte Rosenbaum for organizing the school.

Conflicts of Interest: The authors declare no conflict of interest. The funders had no role in the design of the study, in the writing of the manuscript, or in the decision to publish the results.

\section{References}

1. International Panel on Climate Change (IPCC). Climate Change 2013: The Physical Science Basis. Contribution of Working Group I to the Fifth Assessment Report of the Intergovernmental Panel on Climate Change; Stocker, T.F., Qin, D., Plattner, G.K., Tignor, M., Allen, S.K., Boschung, J., Nauels, A., Xia, Y., Bex, V., Midgley, P.M., Eds.; Cambridge University Press: Cambridge, UK; New York, NY, USA, 2013; ISBN 978-92-9169-138-8.

2. Mach, K.J.; Kraan, C.M.; Adger, W.N.; Buhaug, H.; Burke, M.; Fearon, J.D.; Field, C.B.; Hendrix, C.S.; Maystadt, J.-F.; O'Loughlin, J.; et al. Climate as a risk factor for armed conflict. Nature 2019, 571, 193-197. [CrossRef] [PubMed]

3. Rehfeld, K.; Münch, T.; Ho, S.L.; Laepple, T. Global patterns of declining temperature variability from the Last Glacial Maximum to the Holocene. Nature 2018, 554, 356-359. [CrossRef] [PubMed]

4. Hesse, T.; Butzin, M.; Bickert, T.; Lohmann, G. A model-data comparison of $\delta^{13} \mathrm{C}$ in the glacial Atlantic Ocean. Paleoceanography 2011, 26. [CrossRef]

5. Ionita, M.; Scholz, P.; Lohmann, G.; Dima, M.; Prange, M. Linkages between atmospheric blocking, sea ice export through Fram Strait and the Atlantic Meridional Overturning Circulation. Sci. Rep. 2016, 6, 32881. [CrossRef] [PubMed]

6. Yang, H.; Lohmann, G.; Wei, W.; Dima, M.; Ionita, M.; Liu, J. Intensification and Poleward Shift of Subtropical Western Boundary Currents in a warming climate. J. Geophys. Res. Ocean. 2016, 121, 4928-4945. [CrossRef]

7. Gierz, P.; Lohmann, G.; Wei, W. Response of Atlantic Overturning to Future Warming in a coupled Atmosphere-Ocean-Ice Sheet Mode. Geophys. Res. Lett. 2015, 42, 6811-6818. [CrossRef]

8. McGuffie, K.; Henderson-Sellers, A. The Climate Modelling Primer, 4th ed.; John Wiley \& Sons, Ltd.: Oxford, UK; Chichester, UK; Hoboken, NJ, USA, 2014; ISBN 978-1-119-94337-2.

9. Lohmann, G.; Schneider, J. Dynamics and predictability of Stommel's box model: A phase space perspective with implications for decadal climate variability. Tellus A Dyn. Meteorol. Oceanogr. 1999, 51, 326-336. [CrossRef]

10. Timmermann, A.; Lohmann, G. Noise-Induced Transitions in a simplified model of the thermohaline circulation. J. Phys. Oceanogr. 2000, 30, 1891-1900. [CrossRef]

11. Claussen, M.; Mysak, L.A.; Weaver, A.J.; Crucifix, M.; Fichefet, T.; Loutre, M.-F.; Weber, S.L.; Alcamo, J.; Alexeev, V.A.; Berger, A.; et al. Earth System Models of Intermediate Complexity: Closing the Gap in the Spectrum of Climate System Models. Clim. Dyn. 2002, 18, 579-586. [CrossRef]

12. Lohmann, G.; Butzin, M.; Eissner, N.; Shi, X.; Stepanek, C. Abrupt climate and weather changes across timescales. Paleoceanogr. Paleoclimatol. 2020, 35, e2019PA003782. [CrossRef]

13. Lohmann, G.; Grosfeld, K.; Wolf-Gladrow, D.; Unnithan, V.; Notholt, J.; Wegner, A. (Eds.) Earth System Science: Bridging the Gaps between Disciplines. Perspectives from a Multi-Disciplinary Helmholtz Research School, 1st ed.; Springer: Heidelberg, Germany; New York, NY, USA; Dordrecht, The Netherlands; London, UK, 2013; ISBN 978-3-642-32235-8.

14. Manduca, C.A.; Kastens, K.A. Fostering knowledge integration in geoscience education. Geoscience and geoscientists: Uniquely equipped to study Earth. Geol. Soc. Am. Spec. Pap. 2012, 486, 183-206. [CrossRef] 
15. Lohmann, G.; Lembke-Jene, L.; Tiedemann, R.; Gong, X.; Scholz, P.; Zou, J.; Shi, X. Challenges in the Paleoclimatic Evolution of the Arctic and Subarctic Pacific since the Last Glacial Period-The Sino-German Pacific-Rctic Experiment (SiGePAX). Challenges 2019, 10, 13. [CrossRef]

16. Scheffran, J.; Battaglini, A. Climate and conflicts: The security risks of global warming. Reg. Environ. Chang. 2011, 11, 27-39. [CrossRef]

17. Deardorff, D.K. Synthesizing Conceptualizations of Intercultural Competence: A Summary and Emerging Themes. In The Sage Handbook of Intercultural Competence; Deardorff, D.K., Ed.; SAGE Publications, Inc.: Los Angeles, CA, USA; London, UK; New Delhi, India; Singapore; Washington, DC, USA, 2009; pp. 264-270. ISBN 978-1-4129-6045-8.

18. United Nations Educational, Scientific and Cultural Organization (UNESCO). UNESCO Guidelines on Intercultural Education; United Nations Educational Scientific and Cultural Organization: Paris, France, 2006; Available online: https://unesdoc.unesco.org/ark:/48223/pf0000147878 (accessed on 1 August 2020).

19. Guo, R.X. Understanding the Chinese Economies, 1st ed.; Elsevier, Academic Press: Oxford, UK; Waltham, MA, USA, 2013; Chapter 14-Doing Business in China; pp. 233-2497. ISBN 13 978-0-12-397826-4.

20. Warren, M. Thousands of scientists are backing the kids striking for climate change. Nature 2019, 567, $291-292$. [CrossRef]

21. Thunberg, G. No One Is Too Small to Make a Difference; Penguin Random House LLC: London, UK, 2019; ISBN 9780143133568.

22. Deardorff, D.K.; Arasaratnam-Smith, L.A. (Eds.) Intercultural Competence in Higher Education. International Approaches, Assessment and Application, 1st ed.; Routledge: Abingdon, UK; New York, NY, USA, 2017; ISBN 978-1-138-69385-2.

23. Woltin, K.A.; Jonas, K.J. Interkulturelle Kompetenz: Begriffe, Methoden und Trainingseffekte. In Diskriminierung und Toleranz: Psychologische Grundlagen und Anwendungsperspektiven; Beelmann, A., Jonas, K.J., Eds.; VS Verlag für Sozialwissenschaften: Wiesbaden, Germany, 2009; pp. 463-487. ISBN 9783531157320. Available online: https://hdl.handle.net/11245/1.315695 (accessed on 1 August 2020).

(C) 2020 by the authors. Licensee MDPI, Basel, Switzerland. This article is an open access article distributed under the terms and conditions of the Creative Commons Attribution (CC BY) license (http://creativecommons.org/licenses/by/4.0/). 